\title{
USE OF RELATIVE IONIZATION FOR PARTICLE IDENTIFICATION IN MULTITRAGK SPARK GHAMBER PICTURES
}

C. T COFFIN, L J CURTIS, D I MEYER and $K$ M TERWILIIGER

University of Michigan, Ann Arbor, Michigan

Presented by $\mathrm{K}$ M Terwlliger

In the analysis of pictures from a $>$ park chamber experiment at the Cosmotron, $15 \mathrm{GeV} / \mathrm{c} \tau^{-}+\mathrm{p}$ $\rightarrow A^{0}+\mathrm{K}^{0}-x^{0}$, where the $A^{0}$ and $\mathrm{K}^{0}$ decdr in the chamber, we often noticed considerable differences in the spark densities of the four tiack of a given event Occasionally the effect was quite track density with particle vclocity for a group of assockited production events

The spark chamber used in the experment is - milar to those we descubed in the 1960 Instrumentation (onference ${ }^{1}$ ) and $196 \mathrm{l}$ ppask (hamber

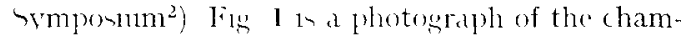

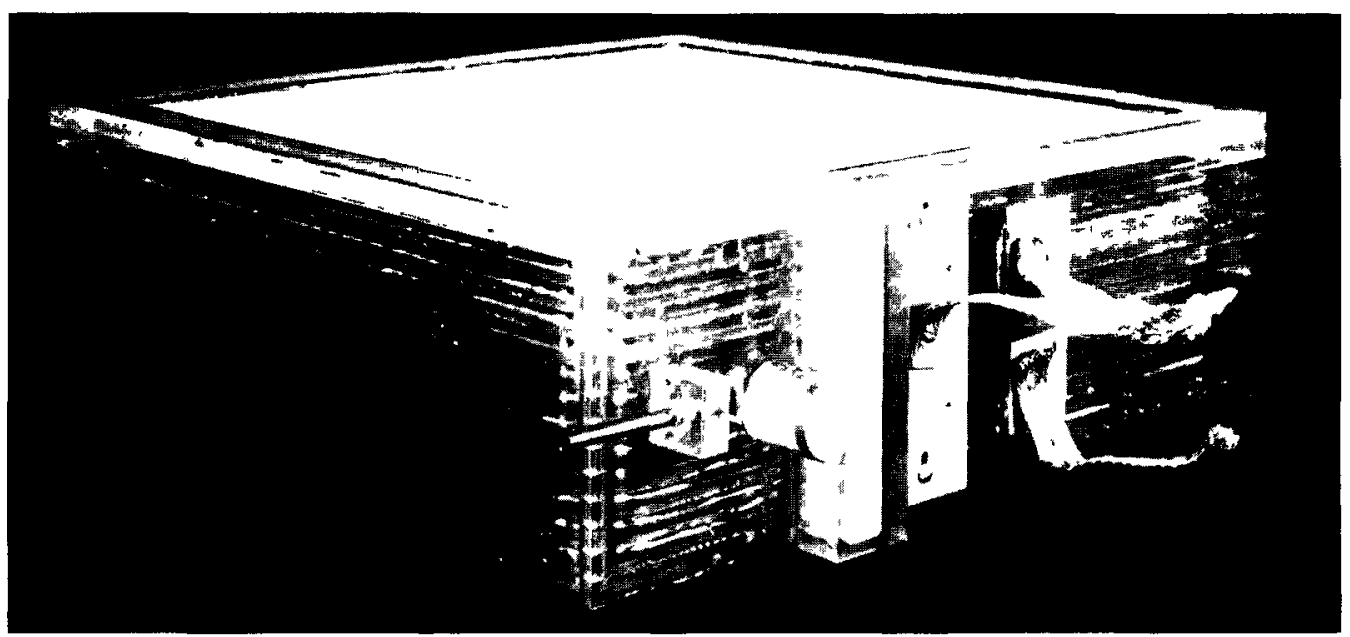

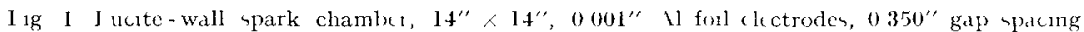

strikıng, with one track very heavy, the other, very light We then compared the relative track densities with the particle velocities calculated from the reaction kinematics, and found nearly complete correlation the lower velocity particles were making the denser sparks This paper will briefly describe the spark chamber system used, show some sets of tracks along with the calculated velocities, and give the results of a comparison of bei It is $14^{\prime \prime} \times 14^{\prime \prime}$ with 12 gaps of $0350^{\prime \prime}$ spacing The walls are $1^{\prime \prime}$ thick lucite picture frames $1 \mathrm{mil}$ half hard $\mathrm{Al}$ forl is bonded to the frames with epoxy iesin, all sections are stacked up in a jlg and the epoxy allowed to harden at around $55^{\circ} \mathrm{F}$. When the chamber is brought up to room temperature the

1) I) Varea and K Jurwilliger, Proc Int (onf Instr H I. Phys, Berkeky (Interscience P'ublishers, N Y 1961) p 276 2) D) Meicrand K Terwilliger, Rev Ser Instr 32 (1961) jls 
folls are stretched tight by the differential coefficient of expansion of the lucite and aluminium There is some crinkling at the edges due to the square geometry, but away from the edges the forl is mirror flat voltage pulse on the chamber was around $300 \mathrm{~ns}$ The $\mathrm{d} c$ clearng voltage was $75 \mathrm{~V}$ The time resolution of the chamber was about $1 \mu \mathrm{s}$ Working in a beam of around $2 \times 10^{4}$ prons per pulse with effectrve pulse length $10-20 \mathrm{~ms}$, most of our events

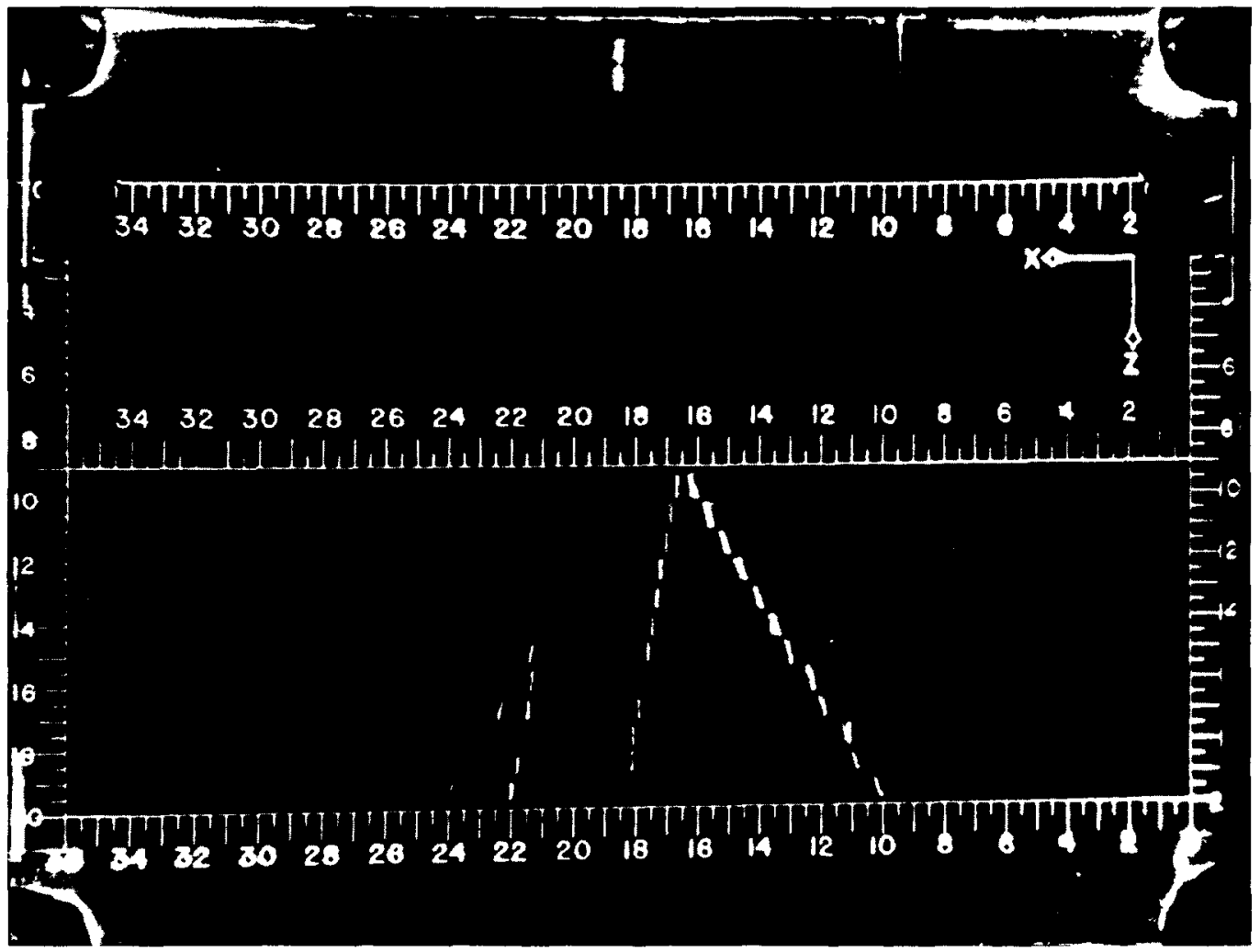

Fig 2 Decdy of $\mathrm{K}^{0}$ and $A^{0} \mathrm{in}$ spark chamber, showing ionization effects $v / c$ computed from kinematics (left to right) $086,099\left(\mathrm{~K}^{0}\right), 073,038\left(\Lambda^{0}\right)$ rhe reticle units are $\mathrm{cm}$

Operating conditions for the chamber were quite standard The chamber was filled with neon gas at atmospherıc pressure, one fillıng lasted three weeks with no appreciable deterioration in chamber behaviour The chamber was pulsed to $10 \mathrm{kV}$ by two 5C22 type hydrogen thyratrons, each pulsed a total capacity of around $1000 \mu \mu \mathrm{F}$, through about $6^{\prime \prime}$ of $\mathbf{l}^{\prime \prime}$ wide lead-in strap from a capacitor of $4000 \mu \mu \mathrm{F}$ The length of the pulse was $100 \mathrm{~ns}$, the overall delay from particle traversal to the high were photographed either alone or with one extra track

Photographs of events showing ionization effects are given in figs 2-4 An incoming $\pi^{-}$, its track above the top reticle, interacts in a liquid $\mathrm{H}_{2}$ target, producing a $A^{0}$ and $\mathrm{K}^{0}$ which decay in the chamber The particle velocities, $v / c$, computed from the kinematics are listed going from left to right across the picture

Examination of a number of such events indicates 
a relatively clear distinction in the track density if the velocities differ by a factor of two or more The differences become marginal for a factor of 13 or less It is also clear that effects other than just ionization are important in determining spark the other $\mathrm{V}$ should be made in the common region, for the closer decaying $\mathrm{V}$ can appear quite a bit heavier in the region where it 1 alone

The contrast betucen tracks varied somewhat from roll to roll, perhaps duc to slow changes in op-

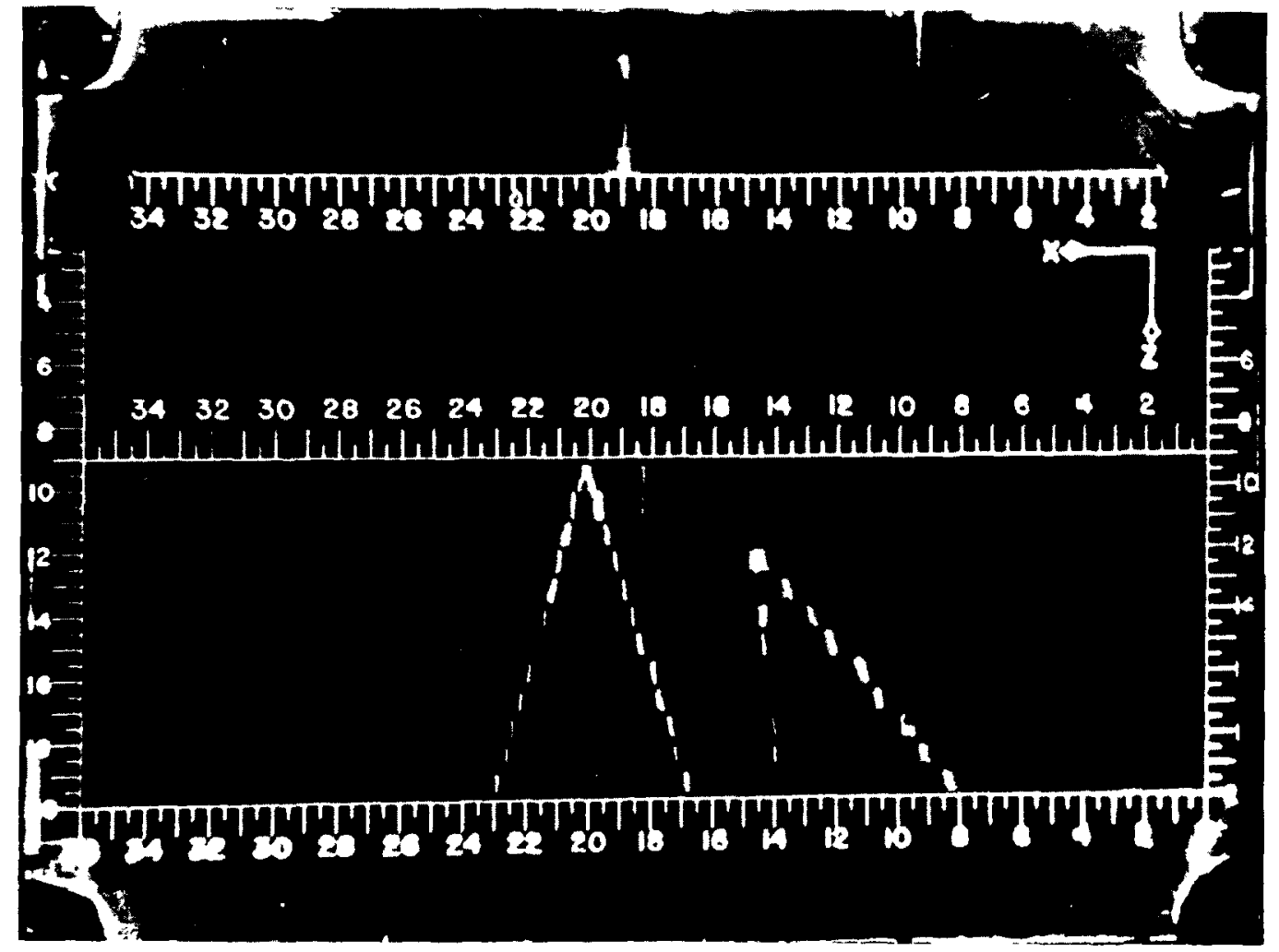

Fig 3 As for fig 2 v/c $099,043\left(\mathrm{~K}^{\circ}\right), 077,032\left(A^{0}\right)$

density and must be taken into account in the particle identification The larger angle tracks, further from the normal to the plates, show up less strongly than the smaller angle tracks for the same velocity Also, the density of a particular track is influenced by its distance from other tracks in the chamber, 1 e if the spark track of one leg of a $V$ is very heavy, the other leg close to it, with a given (higher) velocity, may appear lighter than one of the legs on the other $V$ which has a similar velocity Also, if a $\mathrm{V}$ decays further in the chamber, the comparison between its tracks and eratıng conditions, perhaps to differences in tilm development

In a set of 72 events where the kinematics calculations appeared to give unambiguous results, we made a fairly careful comparison between the track densities and the calculated velocities, taking into account the qualifying effects mentioned above The following results were obtained in 63 events the track densities were consistent with the velocities from the kinematics, and would be a help in particle identification, in 6 events the track densities were too similar and would be of little 
use, in only 3 events was the track density order reversed from the kinematics choice We subsequently used ionization criteria in the rest of our events to confirm kinematics calculations and to resolve ambiguities

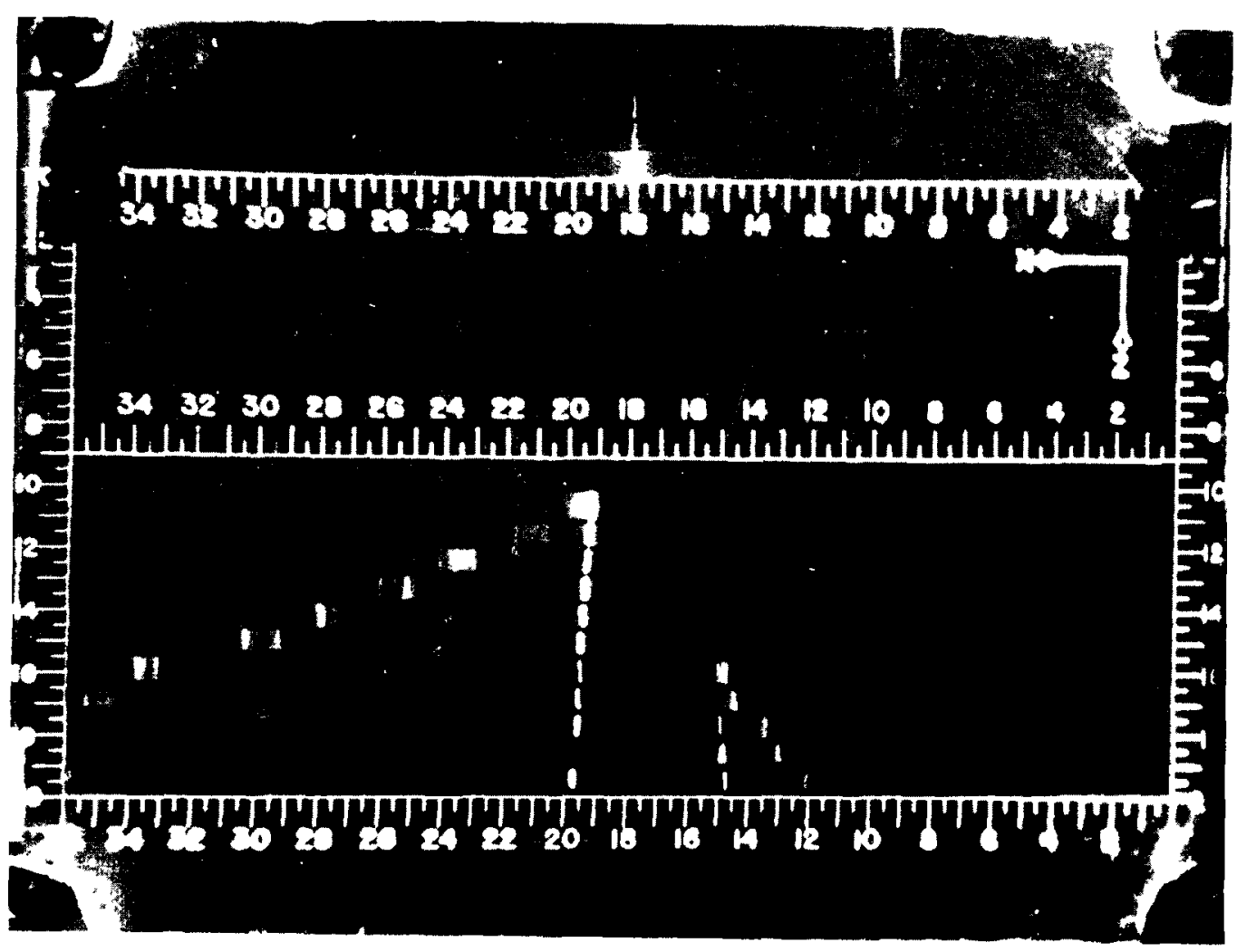

Fig 4 14 for the 2 and 3 vic of $52,064\left(1^{\circ}\right), 097,086\left(K^{0}\right)$

\section{DISGUSSION}

ScHuicz When looking at your pictures one had the impression that often the sparks become less rather than more intense along the track Hou can this be explaned? Is this due to a property of your spark chamber?

Terwillacr These chambors were fired in two sections, 6 gaps each Maybe in the picture you were looking at the furing of the second section occurred later than that of the first 6 gaps The most likely reason, however, 1 s that a second decay $\mathrm{V}$ appeared, robbing some of the charge from the first one

Hayakawa could you give me a little more quantitative statement about the correlation between $\beta$ and brightness?

TERWILLIGER I cannot give to you any more of a quan- titative statement than I already gave We simply vislially observed the relative brightness of tracks and compared that with the $\beta$ 's Cronin has made a more quantitative study actually counting gaps that faled to fire In our chamber most of the gaps usually fired even with four tracks, so we could not use this criterion One could perhaps make a quantitative study of the spark density, but we did not

Winter Does not Cronin's observation of missing gaps as the ionisation of the particle decreases, in contrast $t$ reduced light intensity with full gap efficiency in Teru illiger's report, suggest that the effect is strongly depending on the operation of a spat $k$ chamber, namely on the rise time of the high voltage on the plates?

TERWILliger We, as I said, took no particular precau- 
tions with this chamber We filled it with ordinary neon gas which lasted for three weeks The chamber worked as well at the end as at the beginning of the run The only thing which may be of importance is the rise time of the high voltage pulse

Winter Yes, I think that the main effect is the rise time of the voltage on the plates

FAISSNER We observed the effect even for single particles in case the chamber was running for some reason or another at an average efficiency around $60 \%$ One could try to operate the chamber in this manner as a proportional chamber The difficulty is that the spark density, $1 \mathrm{e}$ the number of sparks per $\mathrm{cm}$, depends so critically on the number, distance, and ionization of the other particles present, as Terwilliger has pointed out I think for a proportional chamber to work one has to divide each plate into a mosaic of independent sections
Cronin Could I ask Faussner what the magnitudes of these effects were?

FaIsSNer In extreme cases the fraction of fired gaps in a pion track coming from a star vaned from about $20 \%$ at the beginning to $100 \%$ at the end of the range

ROBERTS I might add that we have seen exactly the same phenomena in our chamber which is in a magnetic field We observe the same brightening of the proton track in a $\Lambda$ decay This makes the recognition of $\Lambda$ 's an easy task

RoMANowski How did you trigger your spark chambers?

Terwilliger With a 5C22 hydrogen thyratron 